\title{
HELPING SMALL BUSINESSES IDENTIFY THEIR IT APPLICATION NEEDS, A SIMPLE TOOL
}

\author{
Yousif Mustafa, Ph.D., Simplex Systems, Inc., Detroit, MI 48202, drymustafa@gmail.com
}

\begin{abstract}
It is needless to emphasize the importance of small business and the spirit of entrepreneurship innovation that comes along with it. It is a well-known fact that small businesses are the back bone of our economy. This paper presents a unique experience where the author was asked to develop a tool which can be used by small businesses to identify their needs of IT applications. The tool is a computer-based, user-friendly, interactive software, which in the end, will recommend a list of IT applications that a small business must acquire and utilize to match its needs and improve its processes. The project demonstrates many valuable lessons to learn from. The most important one being that an expensive, high-tech, optimal solution is not always the answer. The tool we present in this paper is a very efficient one, based on intuition and common sense and was developed in a relatively short time utilizing low-tech medium.
\end{abstract}

Keywords: Small Business, Excel, Macro, IT Application, Sort, Clustering

\section{INTRODUCTION}

As explained by [2], in addition to its relatively small size within the industry of which it is a part, a small business is one that is (1) actively managed by its owners, (2) highly personalized, (3) largely local in its area of operations, and (4) largely dependent on an internal source of capital to finance its growth. Small businesses constitute the backbone of this nation's economy. In fact, our economy is historically as dependent upon the functions performed by small businesses as it ever was. According to the Office of Advocacy, U.S. Small Business Administration, Jan. 2011. Web. 21 Mar. 2012 [5], small businesses:

$\checkmark \quad$ Represent (99.7\%) of all employer firms.

$\checkmark$ Employ (50\%) of all private sector employees.

$\checkmark$ Pay (44\%) of total U.S. private payroll.

$\checkmark$ Generated (65\%) of net new jobs over the past (17) years.

$\checkmark$ Create more than (50\%) of the nonfarm private GDP.

$\checkmark$ Hire (43\%) of high tech workers (scientists, engineers, computer programmers, and others).

$\checkmark \quad$ Made up (97.5\%) of all identified exporters and produced (31\%) of export value in FY 2008.

$\checkmark$ Produce (13) times more patents per employee than large patenting firms.

In today's environment, whether individually or as a corporation, information technology is penetrating every aspect of our daily lives and invading every little corner. Small businesses are no exception by all means. In order to stay alive, a business can't escape this sweeping wave, or they would be left out in the cold. A business, in today's environment, must implement and utilize IT to its operations and planning in order to successfully interact with its customer base, vendors, and suppliers [7].

\section{THE STORY BEHIND THE TOOL}

While a faculty at the School of Business of a major State University, the author was asked by the SBA office at the school to work with small business owners in the region where the school is located to help identify their needs of IT applications. There were many small businesses in the region including ethnic restaurants, carpentries, weapon repair shops, dairy producers, and farmers. Those owners indicated that they wanted to infuse IT in their work flow. They made it clear to us that they did not want a bunch of vague tips, advises, or academic lectures. They needed 


\section{Issues in Information Systems}

Volume 13, Issue 1, pp. 11-16, 2012

someone to play the role of an "Advisor", analogues to a physician writing a prescription, to tell them explicitly what software packages they must acquire in order to improve their business processes.

It is worthwhile to mention briefly (due to lack of space) that we surveyed the literature and found some previous work which can only be characterized as a number of general tips or common sense guidelines to [3], [4]. However, we have not encountered the existence of a tool, which can systematically examine the current conditions of a small business, assess its needs, and output a listing the IT packages.

Our initial solution was to develop a software tool, which would ask the small business owner a number of questions, then compile a list of software packages depending on the responses to those questions. The tool would ask questions such as:

$\checkmark$ In your daily work, do you need to compose letters? If so, how often?

$\checkmark$ Do you need to crunch numbers and perform calculations?

$\checkmark \quad$ If so, how frequent? How complex? Do you need to draw shapes and charts? If so, how complex? How frequent?

If the response to the first question, for example, is yes, the tool would then recommend purchasing a (word processing) software.

As a typical systems analyst, we conveyed the concept of our initial solution to the SBA office, which strongly rejected the idea because it takes a considerable amount of programming efforts, time, cost, and would be too complex for the small business owners to deal with. The author had one choice after the rejection of the proposed solution; to go back with his/her graduate student to the drawing board and look for another option.

The next section will detail the development of the tool and its functions.

\section{THE PROPOSED TOOL}

A couple of brainstorm sessions opened our eyes to what we would later call "the super market approach". When a customer walks into a super market, he/she isn't asked any questions as to what they want for dinner that evening. The supermarket "displays" all the items along with all the detailed information about the product such as ingredient, expiration date, price, manufacturer, and diet information. The decision after that is solely left up to the customer whether to purchase that item or not.

Building upon this approach, why can't we simply list all the possible standard software packages available on the market and "display" their basic functions allowing the small business owners to make the decision of whether to buy or not?

Accordingly, we built an Excel-based tool, where we listed all the possible software packages in the columns (labeled as S1, S2, S3,.. in Figure 1) and all the employees of the small business in the rows ( labeled as E1, E2, E3,..). On the Excel sheet, when E1 (the small business employee) hovers over S1, for example (which might be Excel, CAD, Visio, or Quickbooks), the tool will display a balloon showing the full details about that software package. After reading the full details about S1, E1 then will be asked to make a decision on whether S1 is instrumental to his/her work and would improve productivity. If so, E1 would enter “1” as a "yes”.

The Excel sheet, we called "Usage Input”, is shown in Figure 1. This sheet simply shows which software package is useful to the target small business. 


\section{Issues in Information Systems}

Volume 13, Issue 1, pp. 11-16, 2012

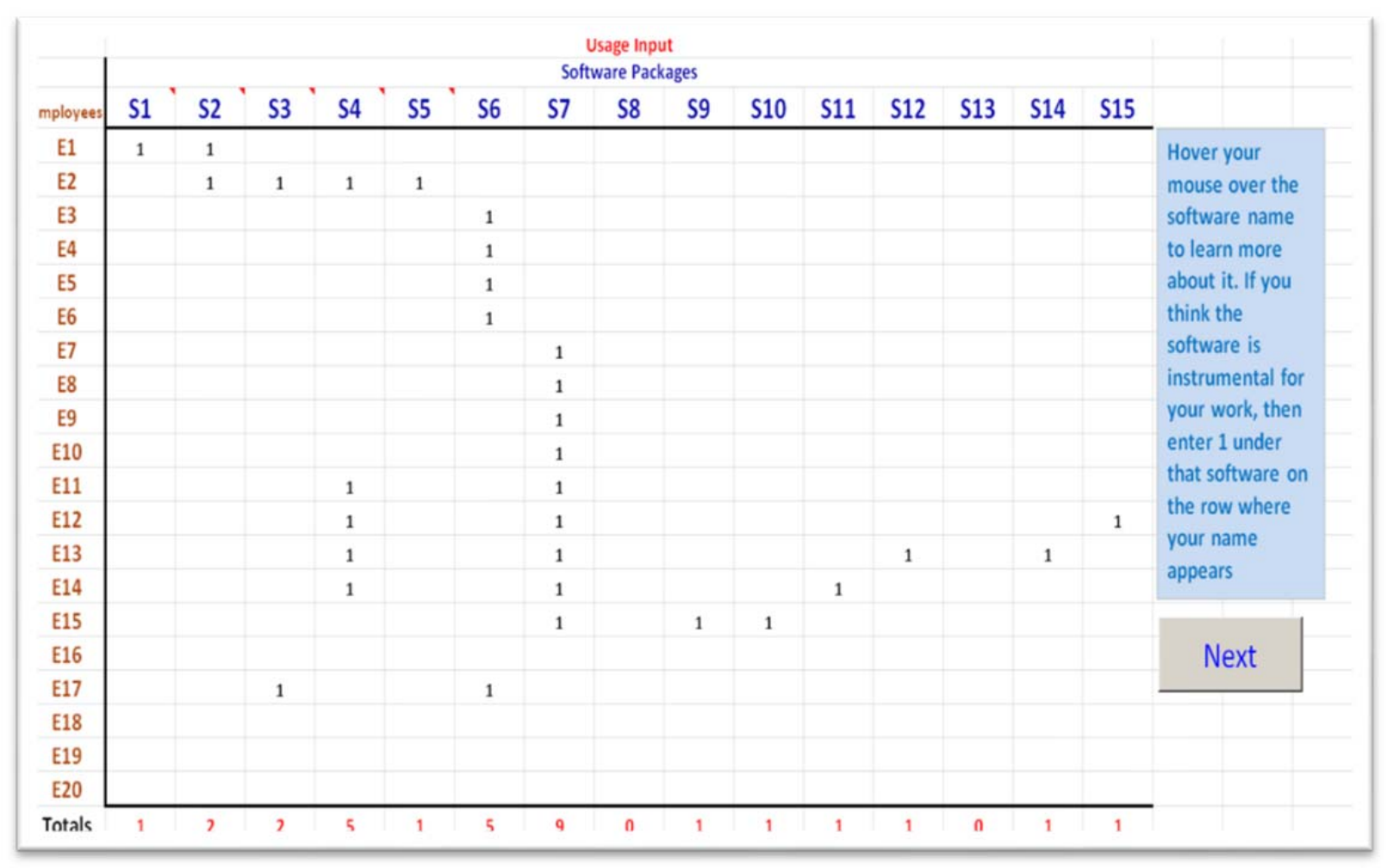

Figure 1.. Usage Input

Figure 1 above shows that 9 employees indicated that S7 would be a very useful software to use in their work. The last row shows the total of the values in each column.

The example we are using here is for demo purpose and due to space limitations, we listed only 10 software packages and 20 employees.

We also added a second Excel sheet (we called "Productivity Input") to receive a more precise data from the employees. The second sheet asks the employees to enter a number between 1 and 10 under the software packages they selected in the first sheet to indicate the extent that a software will impact their productivity and performance with 10 being the highest impact. The sheet is shown in Figure 2. 


\section{Issues in Information Systems}

Volume 13, Issue 1, pp. 11-16, 2012

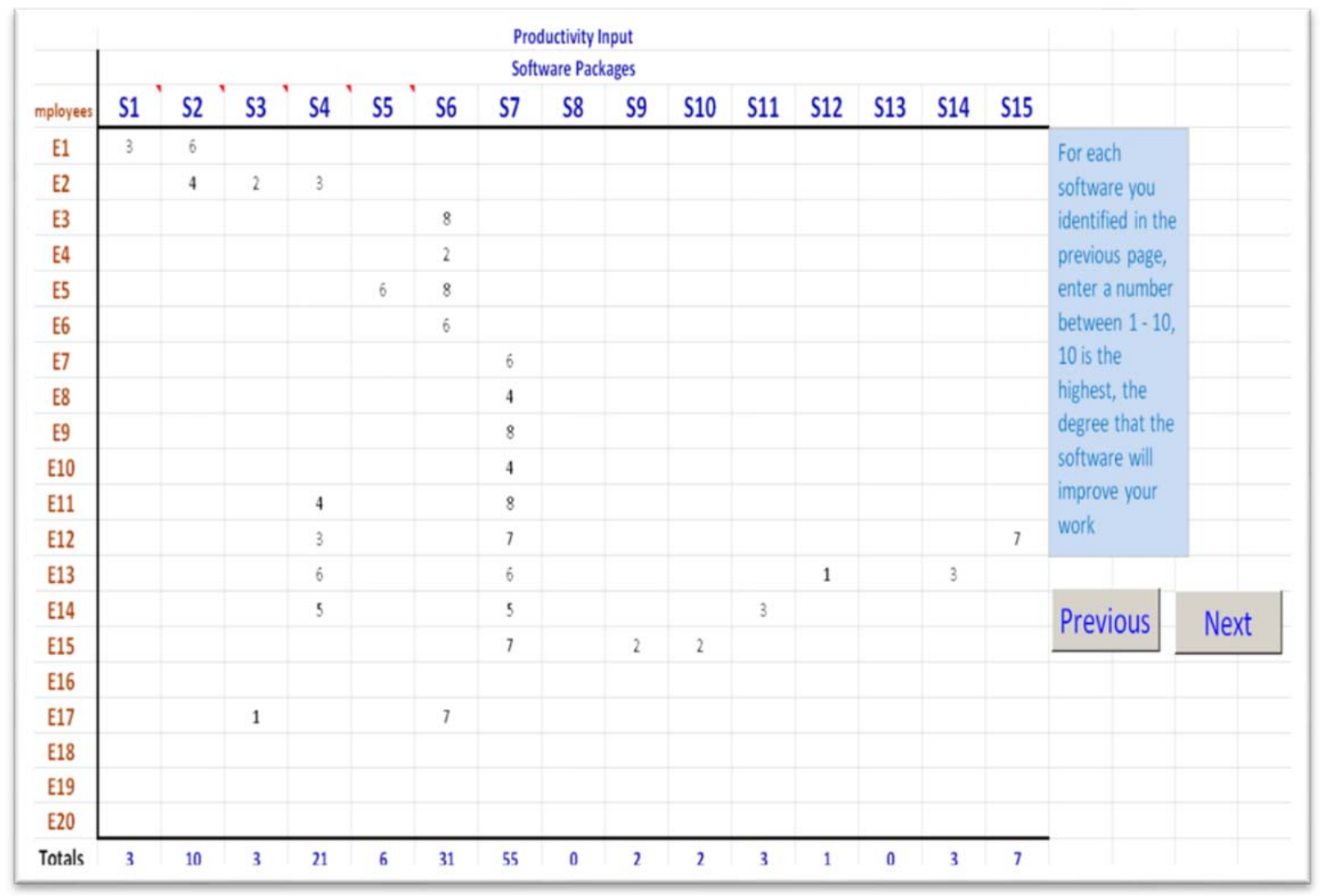

Figure 2. Productivity Input

Figure 2 shows that E12, for example, believes that using software package S15 will have a high impact (7 out of 10) on his/her performance and productivity. The last row shows the total of the values in each column.

These two sheets are the only input data we needed from the small business owners and employees in order to make our final recommendations.

To continue our procedure, we borrowed a clustering concept in cellular manufacturing from [6] and [1]. So, our first step was to simply combine the "Totals" rows of the two sheets together as shown in Figure 3. Combining the two total rows into one row reflects the usability and effectiveness of each software with respect to a certain small business. 


\section{Issues in Information Systems}

Volume 13, Issue 1, pp. 11-16, 2012

\begin{tabular}{|c|c|c|c|c|c|c|c|c|c|c|c|c|c|c|c|c|c|c|}
\hline & \multicolumn{10}{c|}{ This is Your Combined Usage and Productivity Measures } \\
\hline & S1 & S2 & S3 & S4 & S5 & S6 & S7 & S8 & S9 & S10 & S11 & S12 & S13 & S14 & S15 \\
\hline Usage Totals & 1 & 2 & 2 & 5 & 1 & 5 & 9 & 0 & 1 & 1 & 1 & 1 & 0 & 1 & 1 \\
\hline Productivity Totals & 3 & 10 & 3 & 21 & 6 & 31 & 55 & 0 & 2 & 2 & 3 & 1 & 0 & 3 & 7 \\
\hline Grand Totals & 4 & 12 & 5 & 26 & 7 & 36 & 64 & 0 & 3 & 3 & 4 & 2 & 0 & 4 & 8 \\
\hline
\end{tabular}

Figure 3. Combined Usage and Productivity

Next, we sorted the columns in the combined sheet shown in Figure 3 in a descending order based on the totals in the last row. Obviously, the sort will order the software packages by their combined usability and effectiveness. The resulting sorted sheet, shown in Figure 4, represents our recommendations to the small business under consideration.

Figure 4 shows that software package S7 would be the mostly used and has the most impact on productivity followed by S4, while purchasing S8 or S13 would be a waste of money.

\begin{tabular}{|c|c|c|c|c|c|c|c|c|c|c|c|c|c|c|c|}
\hline & \multicolumn{15}{|c|}{ This is Your Prescription from your IT Advisor, Congratulations......... } \\
\hline & \multicolumn{15}{|c|}{ Software Packages } \\
\hline & S7 & S6 & S4 & $\$ 2$ & $\$ 15$ & S5 & S3 & S1 & S11 & \$14 & Sg & $\$ 10$ & S12 & 58 & $\$ 13$ \\
\hline Usage Totals & 9 & 5 & 5 & 2 & 1 & 1 & 2 & 1 & 1 & 1 & 1 & 1 & 1 & 0 & 0 \\
\hline Productivity Totals & 55 & 31 & 21 & 10 & 7 & 6 & 3 & 3 & 3 & 3 & 2 & 2 & 1 & 0 & 0 \\
\hline \multirow[t]{3}{*}{ Grand Totals } & 64 & 36 & 26 & 12 & 8 & 7 & 5 & 4 & 4 & 4 & 3 & 3 & 2 & 0 & 0 \\
\hline & & & & & \multicolumn{2}{|c|}{ Previous } & & & & \multicolumn{2}{|c|}{ Main Menu } & & & & \\
\hline & & & & & & & & & & & & & & & \\
\hline
\end{tabular}

Figure 4. Your IT Prescription 


\section{Issues in Information Systems}

Volume 13, Issue 1, pp. 11-16, 2012

\section{DEPLOYMENT}

After a series of excessive testing, the university SBA office decided to deploy the tool and make it available in a small PC lab dedicated for small business owners in the region free of charge. The office was even gracious enough to install demo copies of a number of those software packages, made available by vendors, for small business owners to try before they buy. However, immediately prior to deployment, we decided to better the tool, enhance its performance, and make it even more easy to use.

To accomplish that, we suggested creating a few versions of the tool to match the various categories of industries or services which would require different sets of software packages. One version would be for a restaurant business, another for a small fabrication shop, and a third for a farming industry.

The systems is a standalone administered by a technician whose tasks are to update the software list frequently, reset and initialize the excel sheets as needed, and help users to utilize the tool.

\section{CONCLUSION}

We believe that there is a strong need for a systematic process for assessing the IT needs for small businesses. We also believe that our approach is an adequate one because:

$\checkmark \quad$ it is based on intuition and common sense

$\checkmark$ extremely user-friendly

$\checkmark$ low development cost

$\checkmark$ flexible where it could be easily expanded to accommodate more software packages and larger number of employees

$\checkmark$ does not require a high level of technical skills for any future maintenance

Finally, the most important lesson we learned from this endeavor is that optimal, fancy, sophisticated, and high-tech solutions are not always the most feasible solution.

We were able to demonstrate through this project that a simple Excel sheet with a few macros could produce an adequate solution to a business problem.

\section{REFERENCES}

1. Askin, R., and Standridge, C. (1993) Modeling and Analysis of Manufacturing Systems, John Wiley, New York.

2. Baumback, C. (1988). How to Organize and Operate a Small Business, Prentice Hall, and New Jersey.

3. Dayton, D. (1997). Information Technology Audit Handbook, Prentice Hall, New Jersey.

4. Fallek, M. (1997). How to Set Up Your Own Small Business, Vol. II, American Institute of Small Business.

5. http://web.sba.gov/faqs/faqindex.cfm?areaID=24

6. Singh, N. (1996). Systems Approach to Computer-Integrated Design and Manufacturing, John Wiley publishing, New York.

7. Williams, M. (1995). Annual Review of Information Science and Technology. Volume 30, ASIS. 